\title{
Palladium-Catalyzed Enantioselective C-H Activation of Aliphatic Amines using Chiral Anionic BINOL-Phosphoric Acid Ligands
}

\author{
Adam P. Smalley, James D. Cuthbertson, and Matthew J. Gaunt* \\ Department of Chemistry, University of Cambridge, Lensfield Road, Cambridge CB2 1EW, United Kingdom
}

Supporting Information Placeholder

\begin{abstract}
The design of an enantioselective Pd(II)-catalyzed C$\mathrm{H}$ amination reaction enabled by a comprehensive understanding of the reaction mechanism is described. The use of a chiral BINOL phosphoric acid ligand enables the conversion of readily available amines into synthetically valuable aziridines in high enantiomeric ratios. The aziridines can be derivatized to afford a range of chiral amine building blocks incorporating motifs readily encountered in pharmaceutically relevant molecules.
\end{abstract}

The development of catalytic enantioselective aliphatic $\mathrm{C}-\mathrm{H}$ bond functionalization processes represents an important challenge for chemical synthesis. ${ }^{1}$ Most prominent among the successful advances towards this ideal has been the use of metallo-carbenoid and nitrenoid strategies. ${ }^{2}$ In contrast, processes that are based on enantioselective metal insertion into aliphatic $\mathrm{C}-\mathrm{H}$ bonds remain limited. ${ }^{3}$ Part of the reason for this deficiency is the lack of available chiral ligands that are effective for oxidative $\mathrm{C}-\mathrm{H}$ functionalization with catalysts derived from palladium(II) salts. The most common classes of ligand for metal-catalyzed enantioselective reactions, chiral phosphines, ${ }^{3}$ are generally incompatible with the reactions conditions required for oxidative Pd-catalyzed $\mathrm{C}-\mathrm{H}$ bond functionalization. As a result, the design of novel classes of ligands for $\mathrm{Pd}$ (II) catalysts has been the focus of significant attention in the synthetic community (Figure 1a). ${ }^{4}$

The catalytic enantioselective desymmetrization of prochiral methyl groups via $\mathrm{Pd}$-catalyzed $\mathrm{Csp}^{3}-\mathrm{H}$ activation represents a potentially useful strategy for the generation of compounds displaying nonracemic fully substituted carbon atoms. To date, however, successful examples of this ideal remain limited. Enantioselective desymmetrization of prochiral methyl groups has been successfully achieved using $\operatorname{Pd}(0)$-catalyzed methods; Kagan, Baudoin, Kundig and Cramer have all reported variations on a $\mathrm{C}-\mathrm{H}$ amination to indolines. ${ }^{3}$ Less common are successful examples of enantioselective oxidative $\mathrm{C}-\mathrm{H}$ desymmetrization using $\mathrm{Pd}(\mathrm{II})$-catalysts. For example, $\mathrm{Yu}$ and co-workers have reported a $\mathrm{Pd}(\mathrm{II})$-mediated, chiral auxiliary-controlled disatereoselective $\mathrm{C}-\mathrm{H}$ iodination of oxazolines, ${ }^{4 \mathrm{a}}$ and $\mathrm{Pd}(\mathrm{II})$-catalyzed $\mathrm{C}-\mathrm{H}$ functionalizations controlled by amino acid-based ligands that give moderate but promising levels of enantioselectivity for alkylation and arylation reactions. ${ }^{4 \mathrm{~b}, \mathrm{c}}$ Related to this, our own efforts identified that similar amino-acid derived ligands enable $\mathrm{Pd}(\mathrm{II})$-catalyzed enantioselective arylation of tetramethyl-piperidine with moderate enantioselectivity. ${ }^{5 c}$

Our laboratory has been engaged in the development a series of processes for the Pd-catalyzed $\mathrm{C}-\mathrm{H}$ functionalization of free $(\mathrm{NH})$ aliphatic amines. ${ }^{5}$ Central to the success of many of these reactions has been the presence of a putative hydrogen bond between the NH motif of a ligated amine and the carbonyl oxygen atom of the Pd-bound car- boxylate..$^{5 b}$ For example, in the case of tetramethylmorpholinone $1 \mathrm{a}$, a hydrogen bond helps to arrange the $\mathrm{C}-\mathrm{H}$ bond into the ideal orientation for $\mathrm{C}-\mathrm{H}$ activation with a second $\mathrm{Pd}$-bound carboxylate (int-I, Figure $1 \mathrm{~b}$ ). Based on this, we reasoned that deployment of a chiral carboxylate or related anionic ligand might lead to a scenario wherein the irreversible $\mathrm{C}-\mathrm{H}$ bond cleavage step would be rendered enantioselective via the desymmetrization of two prochiral methyl groups, leading ultimately to non-racemic aliphatic amine products.

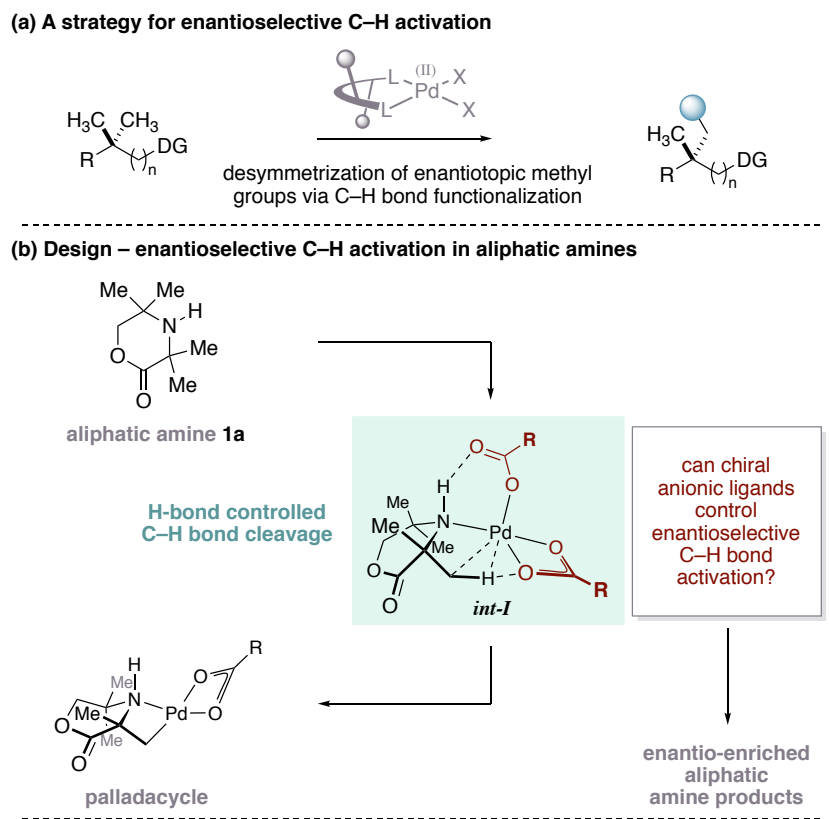

(c) Pd-catalyzed enantioselective $\mathrm{C}-\mathrm{H}$ amination to aziridines

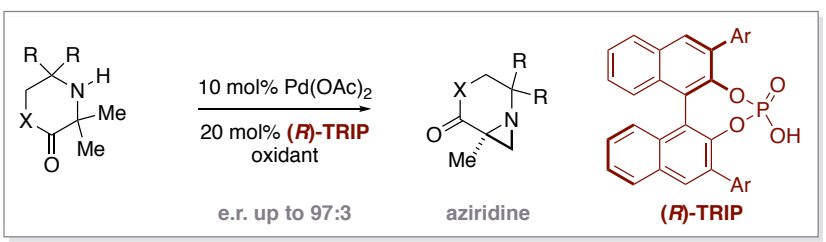

Figure 1. A strategy towards anionic ligand-controlled enantioselective $\mathrm{Pd}$-catalyzed $\mathrm{C}-\mathrm{H}$ activation

The use of chiral anionic ligands to control enantioselective $\mathrm{C}-\mathrm{H}$ activation with palladium catalysts has only recently received attention. Aside from the deployment of chiral amino acid derivatives as bidentate ligands, ${ }^{4}$ Duan et al have described the use of BINOL-derived phosphoric acids ${ }^{6,7}$ to impart modest enantioselective in a methylene $\mathrm{C}-\mathrm{H}$ arylation reaction. ${ }^{8}$ Based on this seminal discovery, two further reports detailing chiral BINOL-phosphates as effective ligands for 
enantioselective $\mathrm{C}-\mathrm{H}$ activation recently emerged; $\mathrm{Yu}$ and co-workers detailed a highly selective enantiotopic methylene $\mathrm{C}-\mathrm{H}$ arylation in thioamide derivatives ${ }^{9 \mathrm{a}}$ and $\mathrm{Chen}$ et al reported an auxiliary-directed $\mathrm{C}-\mathrm{H}$ arylation of amide derivatives..$^{9 \mathrm{~b}}$ Here, we report our own studies on the use of a BINOL-phosphoric acid derivative, ${ }^{6}$ as a chiral anionic ligand, ${ }^{7}$ to enable the Pd-catalyzed enantioselective $\mathrm{C}-\mathrm{H}$ amination of aliphatic amines to form aziridines. High enantioselectivities and yields are obtained for the aziridination process and the products of the reaction can be readily transformed into novel variants of privileged saturated amine hetereocycles, which we believe will be of significant interest to practitioners of medicinal chemistry (Figure 1c).

At the outset of our studies, we tested the enantioselective $\mathrm{C}-\mathrm{H}$ amination of morpholinone $1 \mathrm{a}$, to give aziridine $\mathbf{2} \mathrm{a}$, by screening a range of chiral acids in combination with $5 \mathrm{~mol} \% \mathrm{Pd}(\mathrm{OAc})_{2}$ and phenyliodosyldiacetate (PIDA) in toluene at $70{ }^{\circ} \mathrm{C}$ (see supporting information for details). Unfortunately, none of these reactions resulted in significant enantioselectivity in the product. However, we did find that when $5 \mathrm{~mol} \%$ of BINOL-derived phosphoric acid (BPA, 3a) was added to the reaction, a $16 \%$ yield and a low enantiomeric ratio (e.r.) of 53:47 was observed (Table 1, entry 1 ). Based on this, we tested the 3,3'diaryl-BINOL phosphoric acid, $(R)$-TRIP $\mathbf{3 b}$, under the same conditions and found that although the e.r. had risen slightly to 55:45, the yield (by GC) was improved to $70 \%$ (entry 2). A screen of solvents revealed that reaction in EtOAc or 1,4-dioxane increased the e.r. of the products to 79:21 and 86.5:23.5 respectively, and with moderate yields (entries 4,5); notably, the reaction in dioxane did not reach completion. The addition of 2 equivalents of $\mathrm{Ac}_{2} \mathrm{O}$ did not significantly affect the reaction (entry 9). We also found that the addition of 20 equivalents of $\mathrm{AcOH}$, found to be beneficial in the racemic reaction, ${ }^{5 \mathrm{~b}}$ reduced the reaction to an almost racemic process, albeit in high yield (entry 10). Reducing the concentration to $0.05 \mathrm{M}$ increased the yield of the product to $71 \%$ and the e.r. to $84: 16$ (entry 11 ). We next increased the amount of $(R)$-TRIP in the reaction to maximize the formation of the chiral-palladium catalyst, thereby minimizing any nonchiral background reaction involving $\mathrm{Pd}(\mathrm{OAc})_{2}$; using $10 \mathrm{~mol} \%$ of $(R)$ -
TRIP with $5 \mathrm{~mol} \% \mathrm{Pd}(\mathrm{OAc})_{2}$ gave an e.r. of $89: 11$ with $67 \%$ yield of $2 \mathrm{a}$ (entry 12). Increasing the loading of $\mathrm{Pd}(\mathrm{OAc})_{2}$ to $10 \mathrm{~mol} \%$, combined with $20 \mathrm{~mol} \%$ of $(R)$-TRIP and the addition of 0.5 equivalents of $\mathrm{Ac}_{2} \mathrm{O}$ gave $79 \%$ yield of the product with an e.r. of 93.5:6.5 (entry 13, Condition A). To the best of our knowledge, this represents the first example of a highly enantioselective $\mathrm{Pd}(\mathrm{II}) / \mathrm{Pd}(\mathrm{IV})$-catalyzed process for desymmetrizing $\mathrm{C}-\mathrm{H}$ functionalization of prochiral methyl groups.

We were conscious that using PIDA as oxidant generates two equivalents of $\mathrm{AcOH}$, whose increasing concentration throughout the reaction may compromise the enantioselectivity of the process (entry 10). Accordingly, we found that use of 'acetate-free' oxidants such as iodosylbenzene or iodine, ${ }^{4 a, 10}$ resulted in an improved enantiomeric ratio of 86:14 and 95:5 respectively, but the yields were dramatically reduced (entries 14,15). ${ }^{11}$ Multiple oxidants were investigated in order to attain catalytic turnover and it was found that addition of $\mathrm{AgOAc}$ improved the yield and maintained the e.r. of the product (entry 16). After further optimization of the reaction parameters (lowering concentration, increasing catalyst loading and increasing temperature) we found that $88 \%$ yield of aziridine product with an e.r. of $96.5: 3.5$ could be obtained (entry 17, Condition B). It is clear that the enantioselectivity depends on a delicate balance between the concentration of $\mathrm{AcOH}$ and the chiral TRIP ligand, suggesting that $\mathrm{AcO}^{-}$can replacing the TRIP ligand on the palladium(II) center at high concentrations of $\mathrm{AcOH}$, leading to racemic turnovers. Therefore, it is possible that using $20 \mathrm{~mol} \%$ of the TRIP ligand offsets this problem, particularly towards the end of the reaction. Furthermore, by using AgOAc, which is heterogeneous in this reaction, we suggest that its insolubility is beneficially modulating the concentration of $\mathrm{AcO}^{-} / \mathrm{AcOH}^{12}$ Taken together, the optimization studies revealed two sets of reaction conditions (A and B) for a Pd-catalyzed enantioselective $\mathrm{C}-\mathrm{H}$ amination to aziridines.

With optimal conditions in hand, we explored the scope of the Pdcatalyzed enantioselective $\mathrm{C}-\mathrm{H}$ amination (Table 2). First, we assessed simple derivatives of the morpholinone scaffold and found that variations at both sides of the free $(\mathrm{NH})$ amine were accommodated. In addition to the tetramethyl morpholinone 1a, a cyclohexyl-derived

\section{Table 1. Selected optimization data for enantioselective $\mathrm{Pd}$-catalyzed $\mathrm{C}-\mathrm{H}$ amination to aziridines}
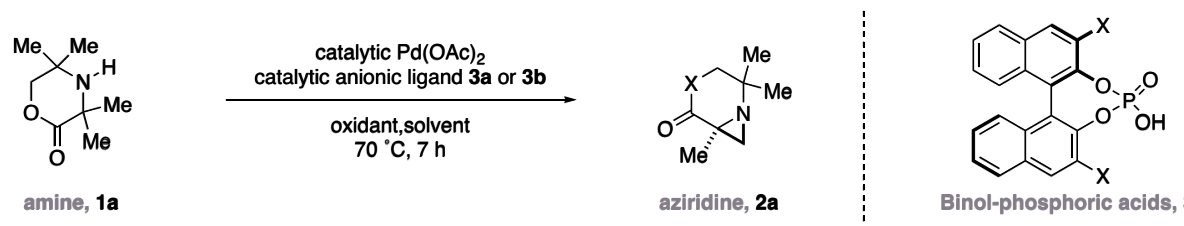

\begin{tabular}{|c|c|c|c|c|c|c|c|c|}
\hline entry & $\mathrm{Pd}(\mathrm{OAc})_{2}, \mathrm{~mol} \%$ & $\begin{array}{c}\text { (R)-TRIP, } \\
\text { mol\% }\end{array}$ & Solvent & Oxidant & $\begin{array}{l}\text { Additives / } \\
\text { comments }\end{array}$ & Conc., $\mathrm{M}$ & Yield (GC) & e.r. (GC) \\
\hline 1 & 5 & 5 (of 3a) & $\mathrm{PhMe}$ & PIDA & - & 0.1 & 16 & $53: 47$ \\
\hline 2 & 5 & 5 & PhMe & PIDA & - & 0.1 & 65 & $55: 45$ \\
\hline 3 & 5 & 5 & $1,2-\mathrm{DCE}$ & PIDA & - & 0.1 & 70 & $61: 39$ \\
\hline 4 & 5 & 5 & EtOAc & PIDA & - & 0.1 & 64 & $79: 21$ \\
\hline 5 & 5 & 5 & 1,4-dioxane & PIDA & - & 0.1 & 44 & $86.5: 23.5$ \\
\hline 6 & 5 & 5 & MeOAc & PIDA & - & 0.1 & 64 & $80: 20$ \\
\hline 7 & 5 & 5 & TBME & PIDA & - & 0.1 & 4 & $80: 20$ \\
\hline 8 & 5 & 5 & DMA & PIDA & - & 0.1 & 32 & $57.5: 42.5$ \\
\hline 9 & 5 & 5 & EtOAc & PIDA & 2 equiv. $\mathrm{Ac}_{2} \mathrm{O}$ & 0.1 & 75 & $78.5: 21.5$ \\
\hline 10 & 5 & 5 & EtOAc & PIDA & 20 equiv. $\mathrm{AcOH}$ & 0.1 & 82 & $52: 48$ \\
\hline 11 & 5 & 5 & EtOAc & PIDA & - & 0.05 & 71 & $84: 16$ \\
\hline 12 & 5 & 10 & EtOAc & PIDA & - & 0.05 & 67 & $89: 11$ \\
\hline $13^{\mathrm{a}}$ & 10 & 20 & EtOAc & PIDA & 0.5 equiv. $A c_{2} \mathrm{O}$ & 0.05 & 79 & 93.5:6.5 \\
\hline 14 & 5 & 5 & EtOAc & $\mathrm{PhI}=\mathrm{O}$ & - & 0.1 & 10 & $86: 14$ \\
\hline 15 & 5 & 10 & EtOAc & $\mathrm{I}_{2}$ & 0.5 equiv. $\mathrm{Ac}_{2} \mathrm{O}$ & 0.05 & 4 & $95: 5$ \\
\hline 16 & 5 & 10 & EtOAc & $\mathrm{I}_{2}, \mathrm{AgOAc}$ & & 0.05 & 86 & $95: 5$ \\
\hline $17^{\mathrm{b}}$ & 10 & 20 & EtOAc & $\mathrm{I}_{2}, \operatorname{AgOAc}$ & $90^{\circ} \mathrm{C}$ & 0.033 & 88 & $96.5: 3.5$ \\
\hline
\end{tabular}

${ }^{\mathrm{a}}$ Condition A. ${ }^{\mathrm{b}}$ Condition $\mathrm{B}$. 
substrate worked effectively in the reaction giving a 95:5 enantiomeric ratio in the product aziridine $\mathbf{2} \mathbf{b}$ with moderate yield.

Table 2. Scope of enantioselective $\mathrm{C}-\mathrm{H}$ amination

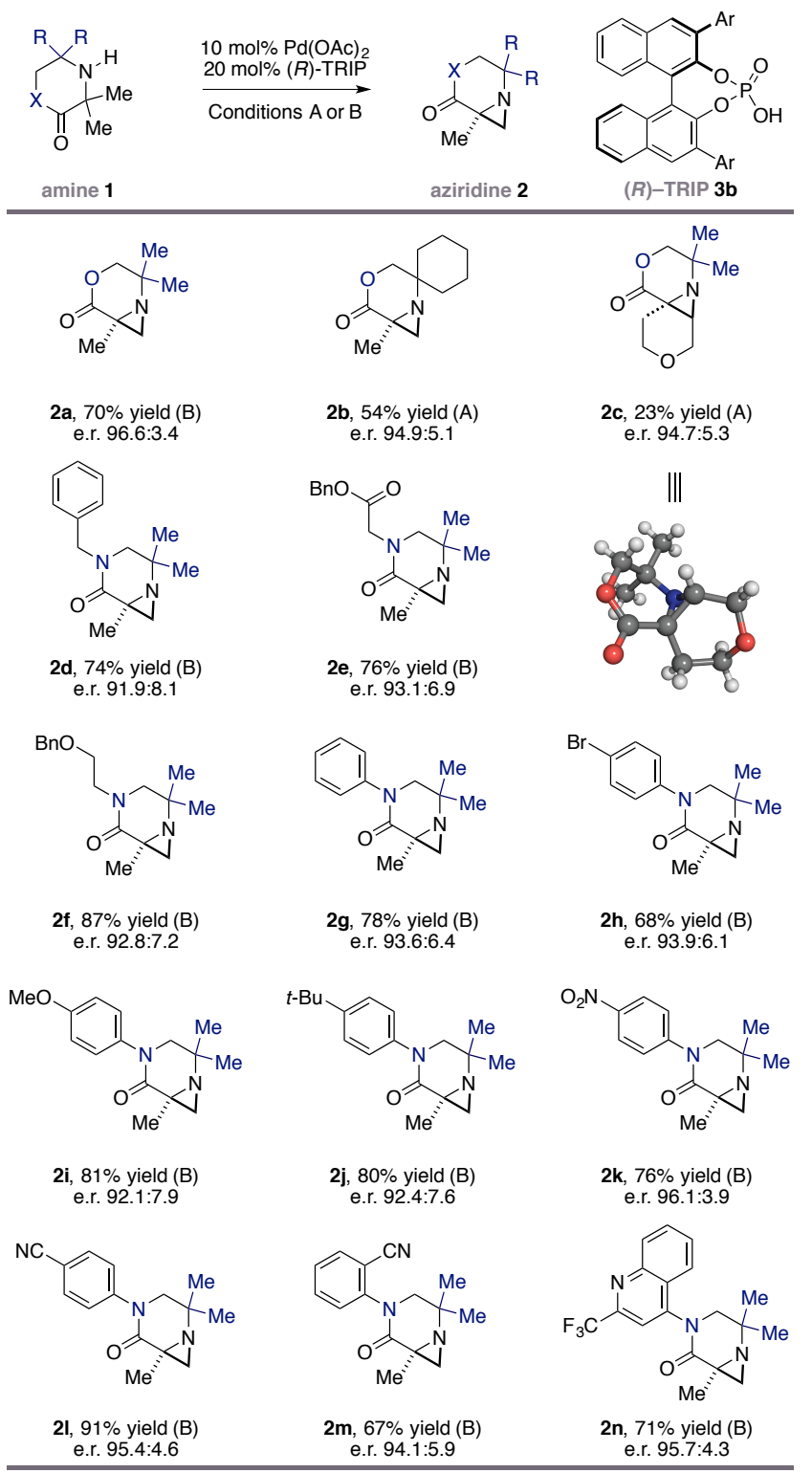

Conditions A: Substrate (1.0 equiv.), $10 \mathrm{~mol} \% \mathrm{Pd}(\mathrm{OAc})_{2}, \mathrm{PhI}(\mathrm{OAc})_{2}$ (2.5-4.0 equiv.), $\mathrm{Ac}_{2} \mathrm{O}$ (0.5 equiv.), $20 \mathrm{~mol} \%(R)$-TRIP, EtOAc (0.05 $\mathrm{M})$. Conditions B: Substrate (1.0 equiv.), $10 \mathrm{~mol} \% \mathrm{Pd}(\mathrm{OAc})_{2}, \mathrm{AgOAc}$ (3.0 equiv.), $\mathrm{I}_{2}$ (2.0 equiv.), 20 mol\% (R)-TRIP, EtOAc $(0.033 \mathrm{M})$. Yields are quoted after flash column chromatography. Chiral analysis was carried out using GC or HPLC.

We were pleased to observe that methylene $\mathrm{C}-\mathrm{H}$ amination to the spirocyclic aziridine $2 \mathrm{c}$ product was also successful with an excellent e.r. of $94.7: 5.3$, the low yield being comparable to that of the racemic reaction. Aziridine $2 \mathrm{c}$ was also crystalline, enabling determination of its absolute configuration via $\mathrm{X}$-ray diffraction. We also investigated the corresponding piperazinone scaffold, wherein the heterocyclic oxygen of the morpholinone is replaced by a nitrogen containing group; successful $\mathrm{C}-\mathrm{H}$ activation on these substrates would substantially broaden the scope of the reaction and provide access to more medicinally relevant heterocyclic products. We were pleased to find that a series of functionalized $\mathrm{N}$-alkyl derivatives containing benzyl, glycinyl, and hydroxylethyl motifs all worked well in the reaction, delivering the aziridine products (2d-f) in good yield and high e.r's. N-Aryl substrates also worked well in the reaction and a range of electronic and steric properties were tolerated, with electron rich $(2 \mathrm{~g}-\mathbf{j})$, electron deficient $(\mathbf{2 k}-\mathbf{m})$ and even Lewis basic heterocyclic motifs $(\mathbf{2 n})$ all providing the corresponding aziridines in good yields and high e.r's.

In considering the pathway through which this enantioselective transformation proceeds, it was important to rationalize the observation that a high concentration of acetate leads to a low enantioselectivity, while an acetate-free system results in a low yield of product. An explanation for this effect could involve an active $\mathrm{Pd}(\mathrm{II})$ complex displaying one acetate and one TRIP ligand. It seems unlikely, based on the size of TRIP, that two of these ligands could be accommodated around the $\mathrm{Pd}(\mathrm{II})$ center; attempts to synthesize $\mathrm{Pd}(\mathrm{TRIP})_{2}$ were unsuccessful. We also noticed a variation in e.r. depending on the electronic properties of the $\mathrm{N}$-aryl group in amines $\mathbf{2 g}-1$. When the $\log ($ e.r. $)$ of the aziridines is plotted against the Hammett $\sigma$ constant of the aryl substituent, one can draw a linear correlation between the enantioselectivity and electronic properties of the group. ${ }^{13}$ Furthermore, it is noticeable that the e.r. in the corresponding morpholinones are higher than the lactam series, possibly reflecting the more electronegative nature of the lactone oxygen atom.

\section{Figure 2. Correlation between e.r. and Hammett constant}

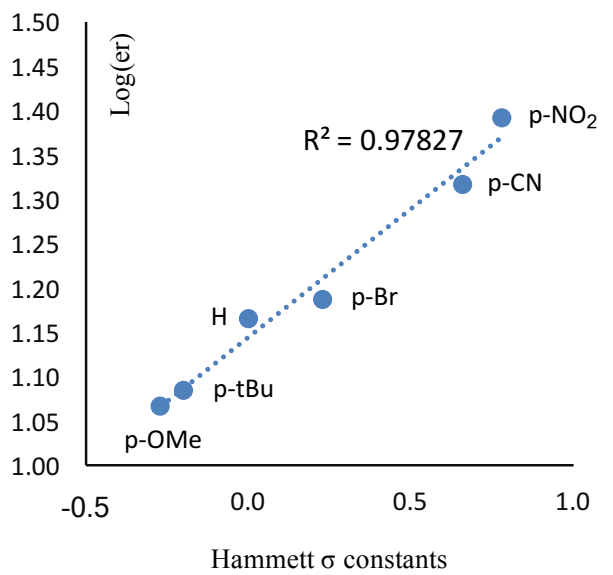

Figure 3. Possible pathways for the enantioselective $\mathrm{C}-\mathrm{H}$ activation (a)
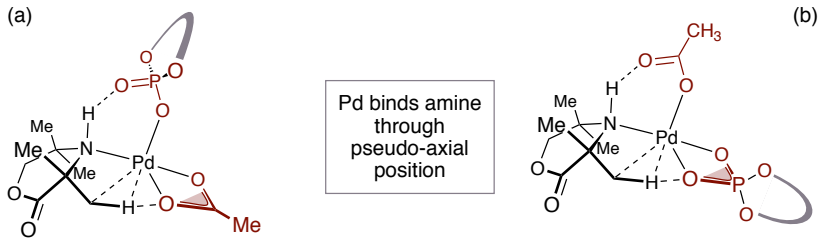

phosphate to $\mathrm{NH}$ hydrogen bond acetate engaged in $\mathrm{C}-\mathrm{H}$ bond cleavage phosphate engaged in $\mathrm{C}-\mathrm{H}$ bond cleavage

We have previously shown that the Pd(II)-catalyst coordinates the free $(\mathrm{NH})$ of the amine through the nitrogen lone pair in the pseudoaxial position, ${ }^{5 b}$ which means that the subsequent $\mathrm{C}-\mathrm{H}$ activation is only possible at the methyl group that is syn to the coordinated metal (pseudo-equatorial on the ring), leading to the four-membered ring cyclopalladation complex. As a result, one scenario could involve a hydrogen bond between the $\mathrm{NH}$ and the phosphate ligand, providing a rigid transition structure for $\mathrm{C}-\mathrm{H}$ bond cleavage via a concertedmetallation-deprotonation type pathway utilizing the acetate group (Figure 3a). ${ }^{14} \mathrm{~A}$ second possibility involves an acetate hydrogen bonding to the ligated amine and the irreversible and enantiodetermining $\mathrm{C}-\mathrm{H}$ bond cleavage mediated by the phosphate ligand (Figure $3 \mathrm{~b}$ ). While these models lay out a preliminary understanding of the factors that influence this reaction, it was not possible, at this stage, to further elucidate which pathway is prevalent, nor the nature of the excellent enantioselectivity observed in this reaction. ${ }^{15}$ Computational studies to 
elucidate the stereocontrolling elements of this catalyst-ligand combination are ongoing and will be reported in due course.

We previously demonstrated that the aziridine ring in the morpholinone-derived products could be opened in the presence of nucleophiles. To test whether the corresponding lactam-aziridines were also compatible with this ring opening transformation, we subjected $\mathbf{2} \mathbf{d}$ to treatment with pyrazole in the presence of p-toluenesulfonic acid to reveal the amide product in $72 \%$ yield. Reduction of the lactam was achieved using $\mathrm{LiAH}_{4}$ in THF to afford highly substituted piperazine 4 in good yield. We also showed that after opening $2 \mathrm{~d}$ with $\mathrm{MeOH}$, a second diastereoselective $\mathrm{C}-\mathrm{H}$ amination takes place to form aziridine 5 in good yield. Aziridine ring opening with pyrazole and subsequent lactam reduction affords piperazine 6 in good yield. We believe that these non-racemic highly functionalized saturated amine heterocycles would be difficult to form by other methods and should be attractive building blocks in medicinal chemistry programs. ${ }^{16}$

Scheme 1. Synthesis of complex amines

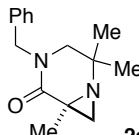

$\underset{\text { (ii) } \mathrm{LiAlH}_{4}, \mathrm{THF}(83 \%)}{\stackrel{\text { (i) pyrazole, p-TsOH }(72 \%)}{\longrightarrow}}$

(iii) $\mathrm{MeOH}, \mathrm{p}-\mathrm{TsOH}(66 \%)$

(iv) $5 \mathrm{~mol} \% \mathrm{Pd}(\mathrm{OAc})_{2}$, PIDA $\mathrm{AcOH}, \mathrm{Ac}_{2} \mathrm{O}$, EtOAc $(69 \%)$ [iterative $\mathrm{C}-\mathrm{H}$ aziridination]

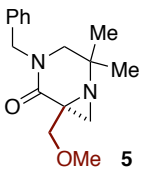

(i) pyrazole, $\mathrm{p}-\mathrm{TsOH}(78 \%)$

(ii) $\mathrm{LiAlH}_{4}$, THF (61\%)

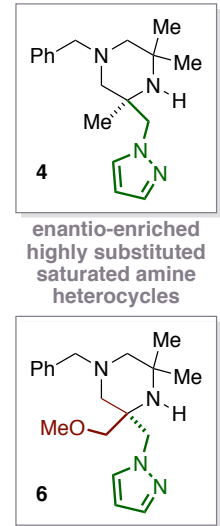

In conclusion, we have developed a Pd-catalyzed enantioselective $\mathrm{C}-\mathrm{H}$ amination to aziridines using anionic BINOL phosphate ligands. A range of amines, displaying prochiral methyl groups, undergo enantioselective desymmeterizing $\mathrm{C}-\mathrm{H}$ activation to produce highly substituted and functionalized products that can be transformed into nonracemic saturated heterocyclic building blocks. While the precise nature of the enantiocontrol imparted by the TRIP ligands remains unclear, we believe that this asymmetric $\mathrm{C}-\mathrm{H}$ activation process will be of significant utility to practitioners of synthetic and medicinal chemistry.

\section{ASSOCIATED CONTENT}

\section{Supporting Information}

Experimental procedures and spectral data. The Supporting Information is available free of charge on the ACS Publications website at

\section{AUTHOR INFORMATION}

\section{Corresponding Author}

*mjg32@cam.ac.uk

\section{Notes}

The authors declare no competing financial interests.

\section{ACKNOWLEDGMENT}

We are grateful to the EPSRC and Pfizer Global Research and Development for an i-CASE studentship (A.P.S.), the European Commission for a Marie Curie International Outgoing Fellowship (J.D.C.), the ERC, Royal Society Wolfson Merit Award and EPSRC for Fellowships (M.J.G.). Mass spectrometry data were acquired at the EPSRC UK National Mass Spectrometry Facility at Swansea University.

\section{REFERENCES}

(1). For an early overview covering enantioselective $\mathrm{C}-\mathrm{H}$ activation; see $\mathrm{Yu}$, J.Q.; Giri, R.; Chen, X. Org. Biomol. Chem. 2006, 4, 4041.

(2). For selected reviews and examples of enantioselective carbene $\mathrm{C}-\mathrm{H}$ insertion; see (a) Davies, H. M. L., Manning, J. D. Nature 2008, 451, 417; (b) Doyle, M. P., Duffy, R., Ratnikov, M., Zhou, L. Chem. Rev. 2010, 110, 704; (c) Davies, H. M. L., Morton, D. Chem. Soc. Rev. 2011, 40, 1857; (d) Liao, K., Negretti, S., Musaev, D. G., Bacsa, J. Davies, H. M. L., Nature 2016, 533. For selected reviews of enantioselective nitrene $\mathrm{C}-\mathrm{H}$ insertion; see (e) Du Bois, J. Org. Process Res. Dev. 2011, 15, 758; (f) Collet, F., Lescot, C., Dauban, P. Chem. Soc. Rev. 2011, 40, 1926

(3). Examples of enantioselctive $\mathrm{Pd}(0)$-catalyzed desymmetrization via $\mathrm{C}\left(\mathrm{sp}^{3}\right)$ $\mathrm{H}$ activation: Examples on Me groups: (a) Anas, S., Cordi, A. Kagan, H. B. Chem. Commun. 2011, 47, 11483; (b) Martin, N., Pierre, C., Davi, M., Jazzar, R., Baudoin, O. Chem. Eur. J. 2012, 18, 4480; (c) Saget, T., Lemouzy, S, Cramer, N. Angew. Chem. Int. Ed. 2012, 51, 2238; (d) Yang, L., Melot, R., Neuberger, M., Baudoin, O. Chem Sci. 2016, advance article, DOI. 10.1039/C6SC04006C. Examples on cycloalkanes: (e) Saget, T., Cramer, N. Angew. Chem. Int. Ed. 2012, 51, 12842; (f) Pedroni, J., Donets, P. A., Cramer, N. Chem. Sci. 2015, 6, 5164; (g) Nakanishi, M., Katayev, D., Besnard, C., Kundig, E. P. Angew. Chem. Int. Ed. 2011, 50, 7438

(4). Examples of $\mathrm{Pd}(\mathrm{II})$-catalyzed desymmetrization via $\mathrm{C}\left(\mathrm{sp}^{3}\right)-\mathrm{H}$ activation. Examples on Me groups: (a) Giri, R., Chen, X., Yu, J. -Q. Angew. Chem. Int. Ed. 2005, 44, 2112; (b) Shi, B. -F., Maugel, N., Zhang, Y. -H., J. -Q. Yu Angew. Chem. Int. Ed. 2008, 47, 4882; (c) Xiao, K.-J., Lin, D. W., Miura, M., Zhu, R. Y., Gong, W., Wasa, M., Yu, J. -Q. J. Am. Chem. Soc. 2014, 136, 8138; (d) Examples on cycloalkanes: (d) Wasa, M.; Engle, K. M.; Lin, D. W.; Yoo, E. J.; Yu, J.-Q.J. Am. Chem. Soc. 2011, 133, 19598; (e) Xiao, K.-J., Lin, D. W., Miura, M., Zhu, R. -Y., Gong, W., Wasa, M., Yu, J. -Q. J. Am. Chem. Soc. 2014, 136, 8138; (f) Chan, K. S. L., Fu, H. -Y., Yu, J. -Q. J. Am. Chem. Soc. 2015, 136, 2042. Enantioselective methylene C-H activation: (g) Chen, G., Gong, W., Zhuang, Z., Andra, M. S., Chen, Y. -Q., Hong, X., Yang, Y. -F., Liu, T. Houk, K. N., Yu, J. -Q. Science 2016, 353, 1023.

(5). (a) McNally, A., Haffemayer, B., Collins, B. S. L., Gaunt, M. J. Nature 2014, 510, 129; (b) Smalley, A. P., Gaunt, M. J. J. Am. Chem. Soc. 2015, 137, 10632; (c) He, C., Gaunt, M. J. Angew. Chem. Int. Ed. 2015, 54, 15840; (d) Calleja, J., Pla, D., Gorman, T. W., Domingo, V., Haffemayer, B., Gaunt, M. J. Nat. Chem. 2015, 7, 1009. (d) Willcox, D., Chappell, B. G. N., Hogg, K. F., Calleja, J., Smalley, A. P., Gaunt, M. J. Science 2016, 354, 851.

(6) (a) Akiyama, T., Itoh, J., Yokota, K., Fuchibe, K. Angew. Chem. Int. Ed. 2004, 43, 1566; (b) Uraguchi, D., Terada, M. J. Am. Chem. Soc. 2004, 126, 5356; (c) Parmar, D., Sugiono, E., Raja, S. \& Rueping, M. Chem. Rev. 2014, 114,9047

(7) (a) Hamilton, G. L., Kang, E. J., Mba, M., Toste, F. D. Science 2007, 317, 496; (b) Mukherjee, S., List, B. J. Am. Chem. Soc. 2007, 129, 11336; (c) Jiang, G., Halder, R., Fang, Y., List, B. Angew. Chem. Int. Ed. 2011, 50, 9752; (d) Chai, Z., Rainey, T. J. J. Am. Chem. Soc. 2012, 134, 3615; (e) Wang, P.-S., Lin, H.-C., Zhai, Y.-J., Han, Z.-Y.; Gong, L.-Z. Angew. Chem. Int. Ed. 2014, 53, 11218.

(8) Yan, S.-B., Zhang, S., Duan, W.-L. Org. Lett. 2015, 17, 2458.

(9) (a) Jain, P., Verma, P., Xia, G. Yu, J. -Q. Nat. Chem. 2016, 353, 1023. (b) Wang, H., Tong, H. -R., He, G., Chen, G. Angew. Chem. Int. Ed. 10.1002/anie.201609337.

(10). Rubottom, G. M., Mott, R. C. J. Org. Chem. 1979, 44, 1731.

(11) Use of PhIO generates water, which we determined degrades the catalyst. ${ }^{5 b}$ Use of $\mathrm{I}_{2}$ leads to inactive $\mathrm{PdI}_{2}$ being formed at the end of the catalytic cycle.

(12) The lower $\mathrm{pH}$ resulting from generation of $\mathrm{AcOH}$ could affect the concentration of the putative $3 \cdot \mathrm{Pd}(\mathrm{OAc})$ species, thereby affecting stereoinduction (13) Neel, A., Millo, A., Toste, F. D., Sigman, M. S. Science, 2015, 347, 737. (14) (a) Rousseaux, S.; Gorelsky, S. I.; Chung, B. K. W.; Fagnou, K. J. Am. Chem. Soc. 2010, 132, 10692. (b) García-Cuadrado, D.; Braga, A. A. C.; Maseras, F.; Echavarren, A. M. J. Am. Chem. Soc. 2006, 128, 1066. (c) Balcells, D.; Clot, E.; Eisenstein, O. Chem. Rev. 2010, 110, 749. (c) Davies, D. L., Donald, S. M. A., Macgregor, S. A. J. Am. Chem. Soc. 2005, 127, 13754.

(15) Simon, L. Goodman, J. M. J. Org. Chem. 2011, 76, 1775.

(16) (a) Lovering, F., Bikker, J., Humblet J. Med. Chem. 2009, 52, 6752; (b) Roughley, S. D., Jordan, A. M. J. Med. Chem. 2011. 54, 3451. 
TOC

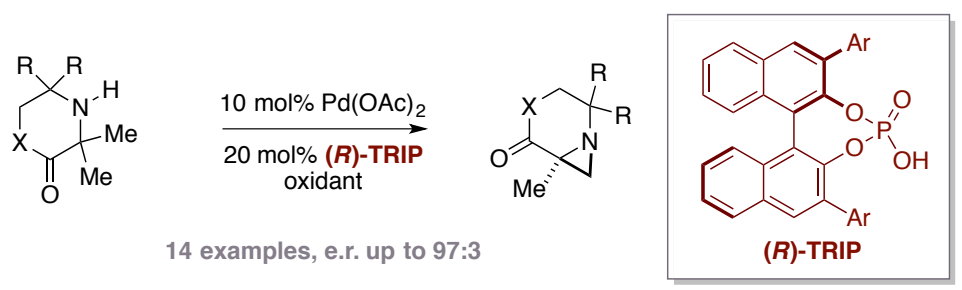

